\title{
The Relationship between Moral Identity, Spiritual Well-being and Religious Orientation with Job Adjustment among Nurses
}

\section{Hamid Reza Samadifard (MSc) ${ }^{1, *}$, Mohammad Narimani (PhD) ${ }^{2}$}

${ }^{1}$ PhD Student of Psychology, Faculty of Educational Sciences and Psychology, University of Mohaghegh Ardabili, Ardabil, Iran

${ }^{2}$ Professor Emeritus, Department of Psychology, Faculty of Educational Sciences and Psychology, University of Mohaghegh Ardabili, Ardabil, Iran

* Corresponding Author: Hamid Reza Samadifard, PhD Student of Psychology, Faculty of Educational Sciences and Psychology, University of Mohaghegh Ardabili, Ardabil, Iran.Email: hrsamadifard@uma.ac.ir

\section{Abstract}

Received: 26/12/2017

Accepted: 23/01/2017

How to Cite this Article:

Samadifard HR, Narimani M. The Relationship between Moral Identity, Spiritual Well-being and Religious Orientation with Job Adjustment among Nurses. Pajouhan Scientific Journal. 2018; 17(1): 1-8. DOI: 10.29252/ psj.17.1.1
Background and Objective: Job adjustment is an important factor to continue the successful employment of nurses. The present study aimed at investigating the relationship between moral identity, spiritual well-being and religious orientation with job adjustment among nurses.

Materials and Methods: This is a cross-sectional correlation study and statistical population of this research were included all female nurses working in government hospitals in Ardabil in 2015 that 120 persons were selected as samples using the available sampling method. Data collection tools included Aquino and Reed moral identity scale (2002), Fisher spiritual well-being scale (2005), Allport religious orientation scale (1968) and Dawis, Lofquist job adjustment scale (1991). Data analysis was conducted by the Pearson correlation coefficient and multiple linear regression tests. The data were analyzed into SPSS v. 23 software.

Results: The findings showed that there is a significant positive relationship between moral identity $(\mathrm{r}=0.63)$ and spiritual well-being $(\mathrm{r}=0.53)$ with job adjustment of nurses. As well as between religious orientation components, there is a significant positive relationship between interior orientation $(\mathrm{r}=0.56)$ with job adjustment and there is a significant negative relationship between exterior orientation $(\mathrm{r}=-0.52)$ with job adjustment $(\mathrm{P}<0.05)$. According to beta coefficients; moral identity, spiritual well-being, and religious orientation predict 0.61 of job adjustment variance in female nurses $(\mathrm{P}<0.05)$.

Conclusion: Nurses' job adjustment is predictable by the moral identity, spiritual well-being and religious orientation. Therefore, it is suggested that psychologists and counselors consider the role of moral identity, spiritual well-being and religious orientation to promote the level of nurses' job adjustment.

Keywords: Moral Identity; Spiritual Well-being; Religious Orientation; Job Adjustment; Nurses 
' انشجوى دكتراى تخصصى روانشناسى، دانشكده علوم تربيتى و روانشناسى، دانشگاه محقق اردبيلى، اردبيل، ايران

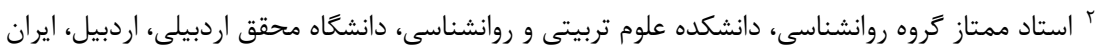

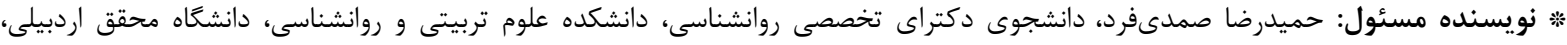
اردبيل، ايران. ايميل: hrsamadifard@uma.ac.ir

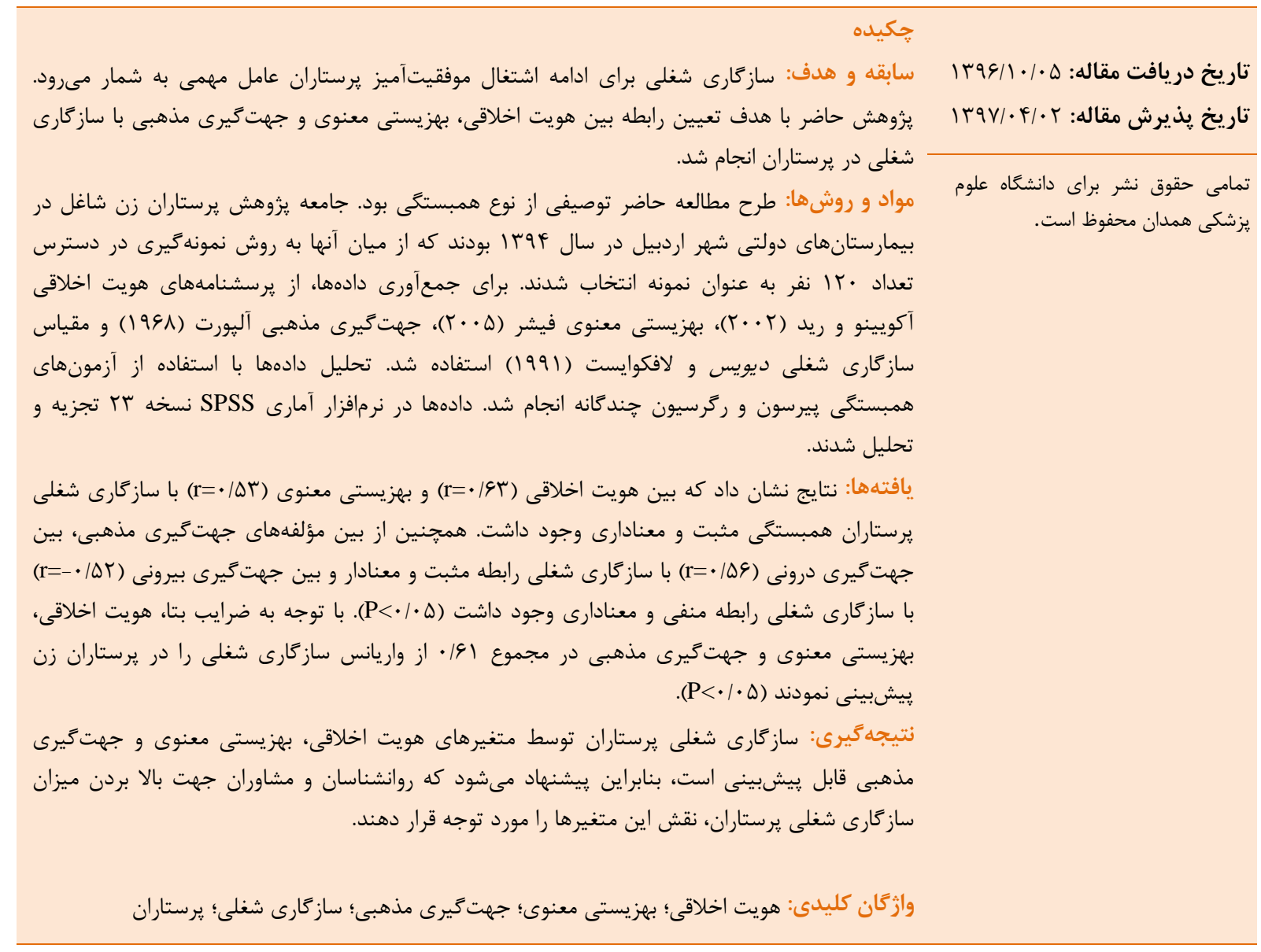

را كاهش دهند، ولى در روش واكنشى، افراد سعى در تغيير

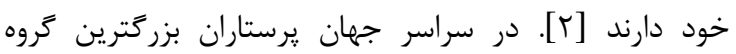

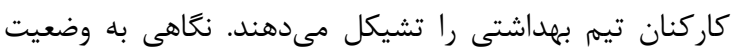

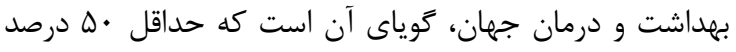

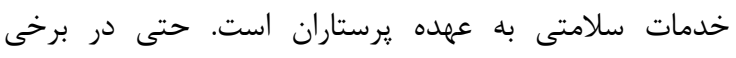
كشورها حدود •^^ درصد امور بهداشتى توسط يرستاران انجام

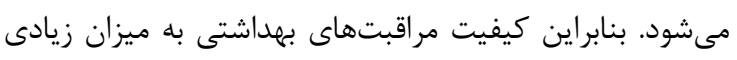

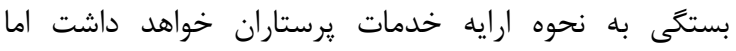

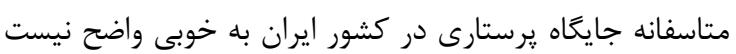

در اكثر سازمانهاى مراقبت بهداشتى، يرستاران بزرگترين

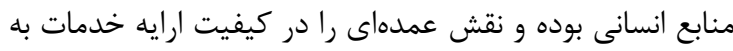

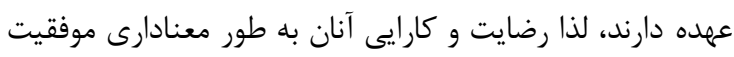

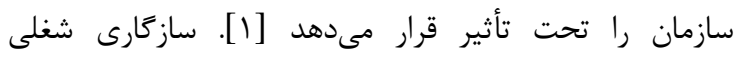

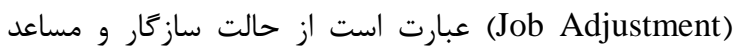
روانى فرد نسبت به شغل مورد نظر رِ يس از اشتغال. معمولاً

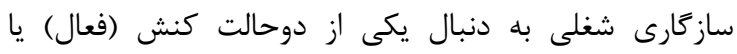

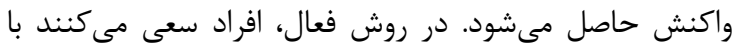

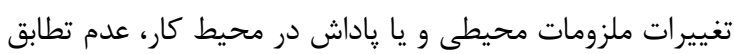




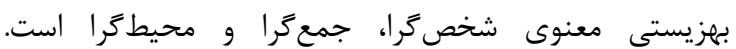
بهزيستى معنوى شخصى يعنى اينكه فرد توانسته بين معنا، هدف و ارزشهاى زندگى خود انسجام و سازگًاى برقرار كند.

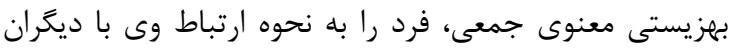

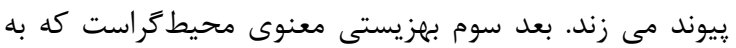

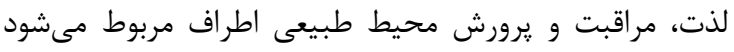

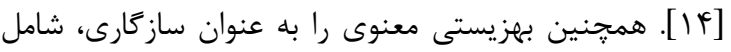

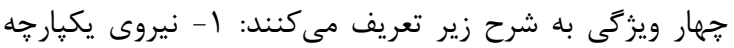

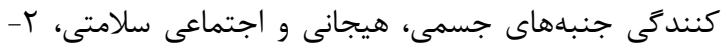

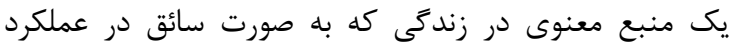

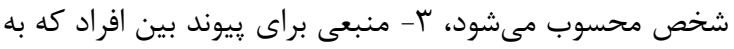

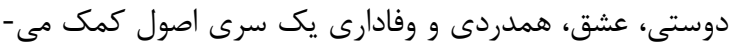

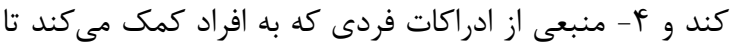

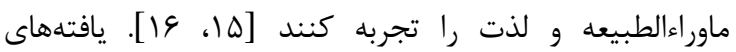
مطالعات مختلف، از نقش بهزيستى معنوى بالا در افزايش

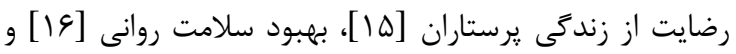

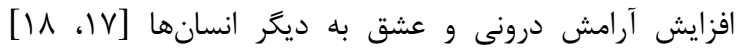
حمايت مى كند.

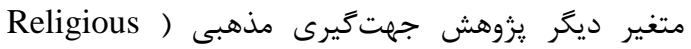
(Orientation

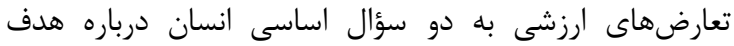

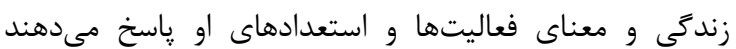

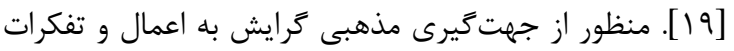

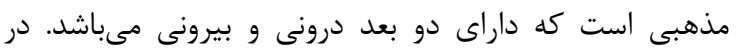

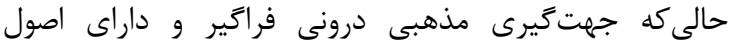
سازمان يافته و درونى است، جهت خارجى است كه براى ارضاى نيازهاى فردى از قبيل ديل مقام و و

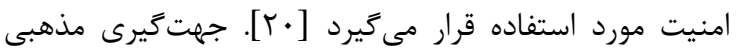
دورنى در معنا ساختن زندگى مانند هدف زندگى موردي، توبه، اميد،

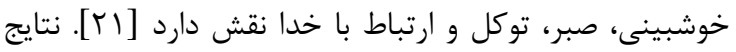

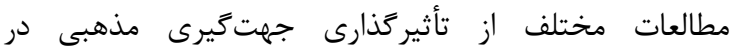

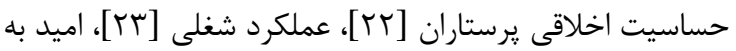

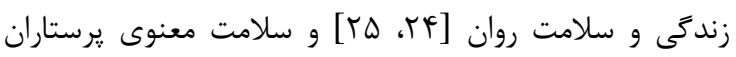
[ [ب]]، حمايت مى كند.

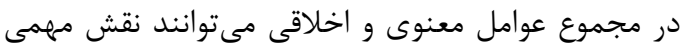
در توانمندىسازى افراد در جنبههاى مختلف زندكى داشى داشته

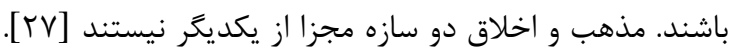

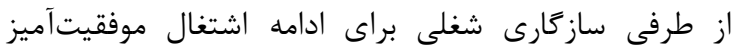

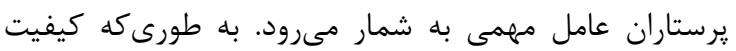

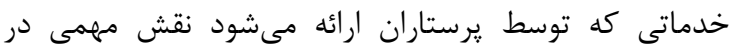

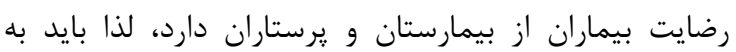

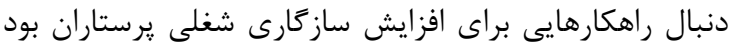

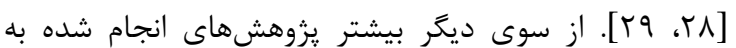

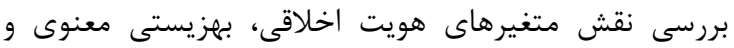

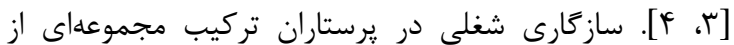

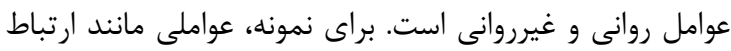

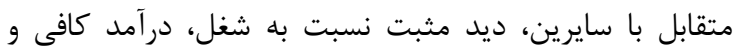

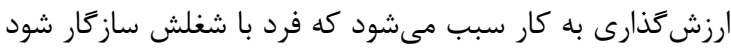

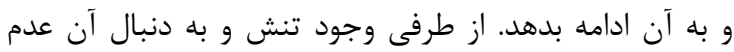

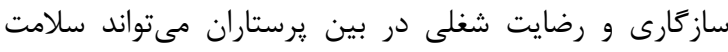

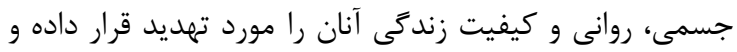

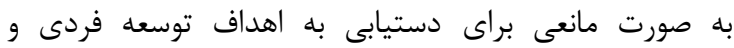

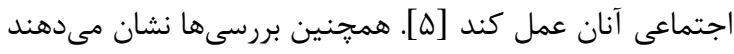

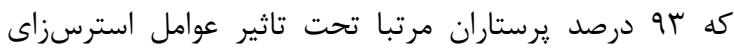

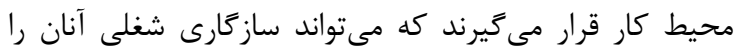

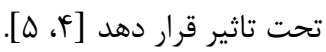

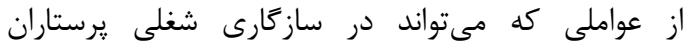

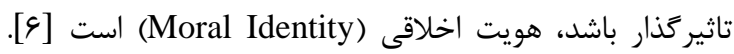
رعايت اخلاق در همه مشاغل با اهميت است اما در حريت حرفه

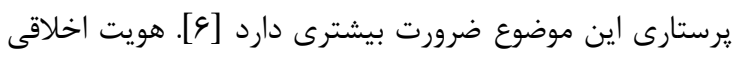

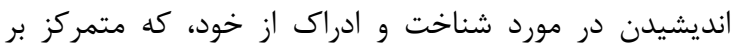

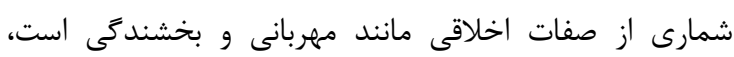

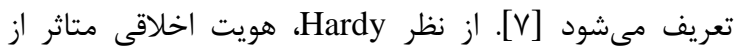

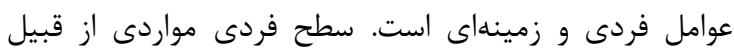

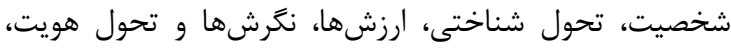
مىتواند بر شكل شيرى هويت اخلاقى اثر بحذارد. در سطح

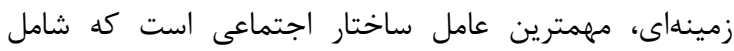

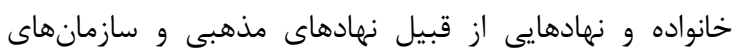

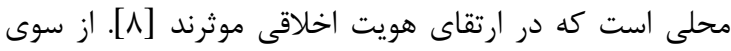
ديخر از عواملى كه در تعهد كارى افراد نقش دارد سازگًارى و رضايت شغلى آنان است كه تحت تاثير عوامل مختلفى دانى مانند

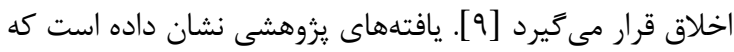

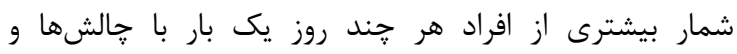

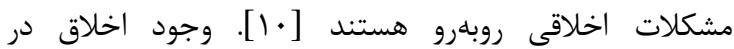

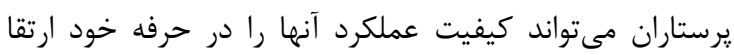

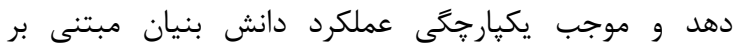
اخلاقيات آنها، در شرايط مختلف شود [11]] جو اخلاقى كه توسط افراد ادراك مىشود، بر سطح رضايت و سازگًارى شغلى دانى

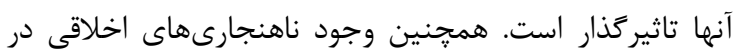

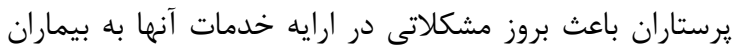

خواهد شد [1 [1]]. از عوامل ديخرى كه مئواند در سازگًارى شغلى يرستاران تاثير كذار باشد، بهزيستى معنوى (Spiritual Well-being)

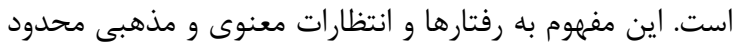

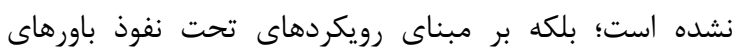

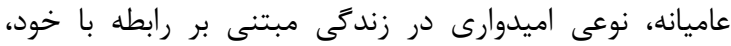

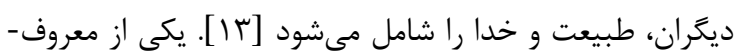
ترين مدلها در بهزيستى معنوى، مدل جند مؤلفهاى شامل مأل 
است [rץ]. لازم به ذكر است، در يزوهش حاضر از نمره كل

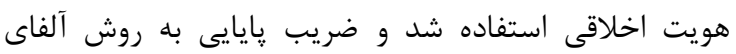

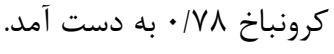

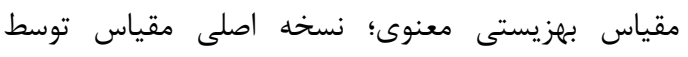
Fisher

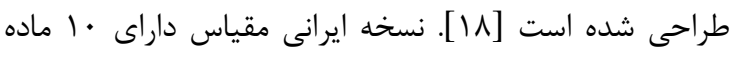

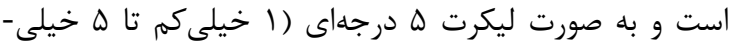

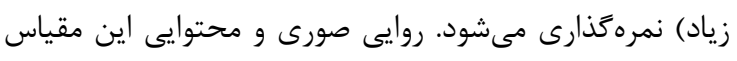

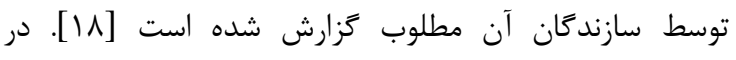

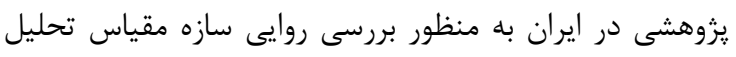

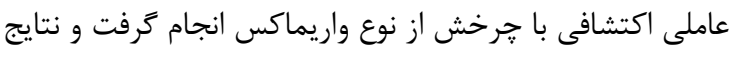

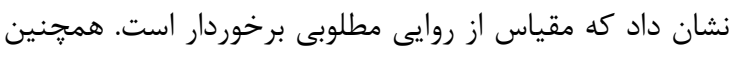

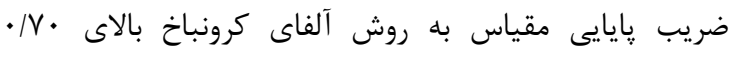

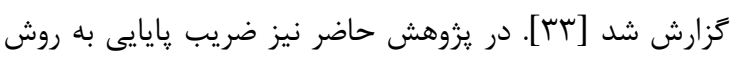

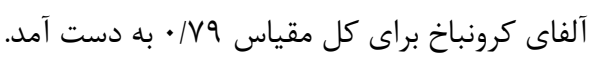

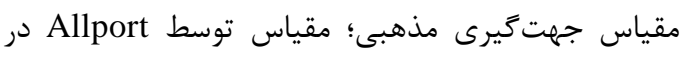

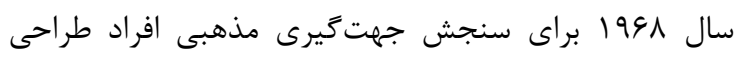

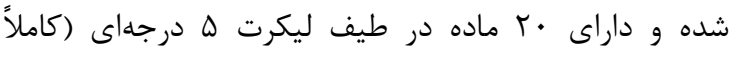

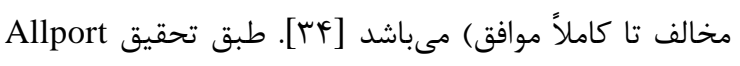

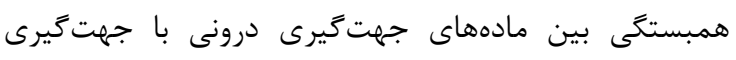

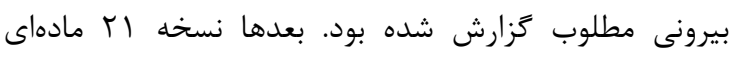

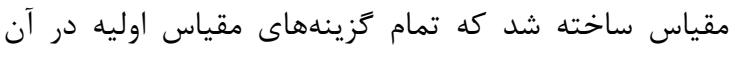

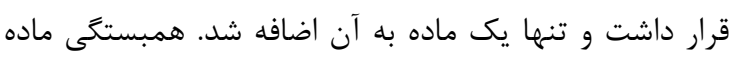

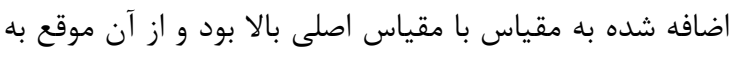

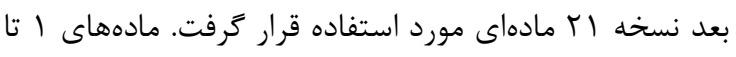

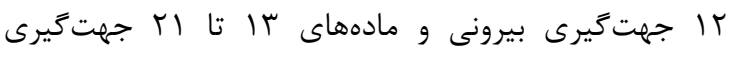

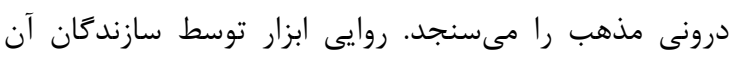

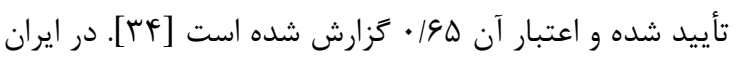

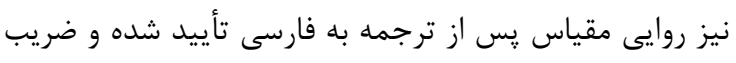

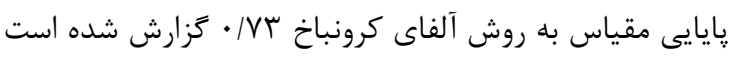

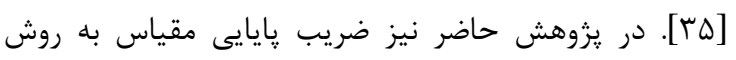

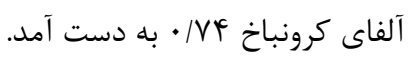

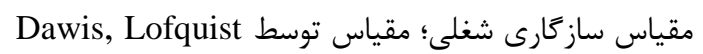

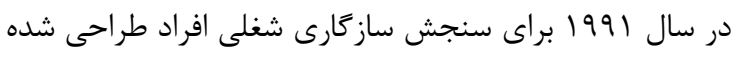

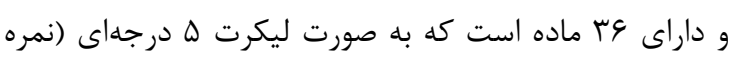

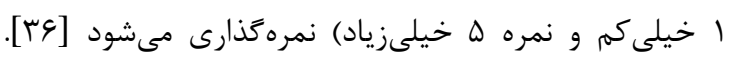

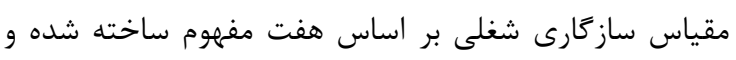

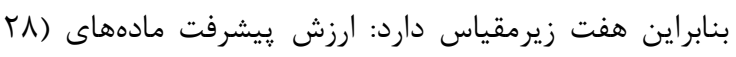

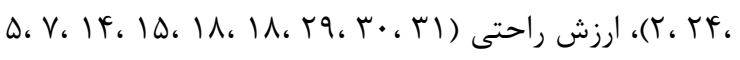

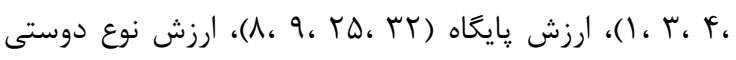

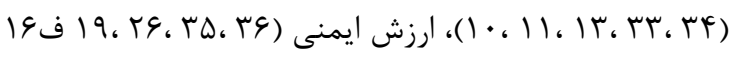

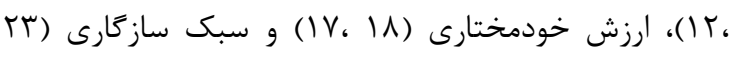

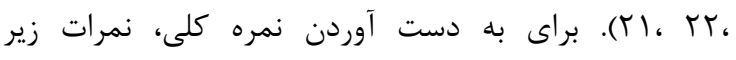

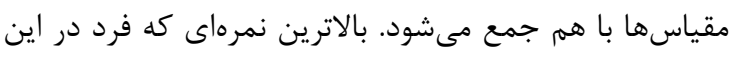

جهت گيرى مذهبى با ابعاد سلامت يرداخته است و در مورد

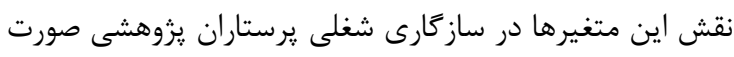

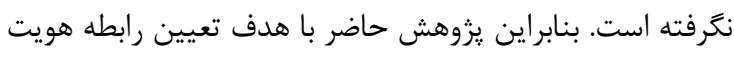

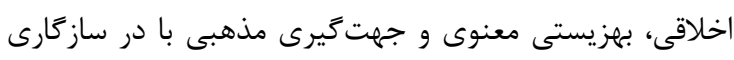
شغلى در بين يرستاران شهر اردبيل انجام شد.

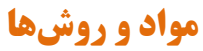

طرح يزوهش حاضر توصيفى از نوع همبستكى بود. جامعه

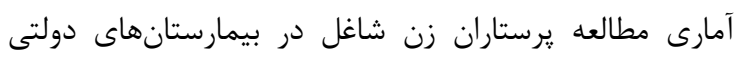

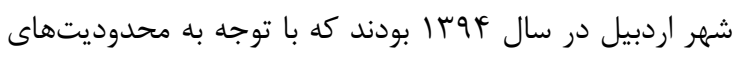

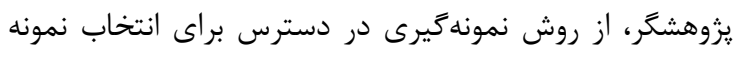

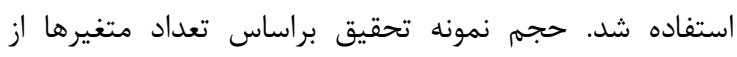

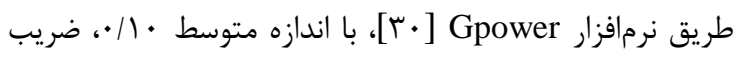

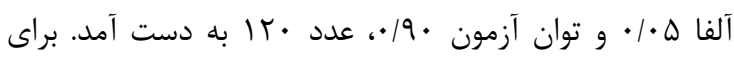

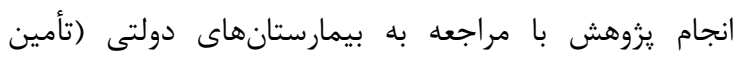

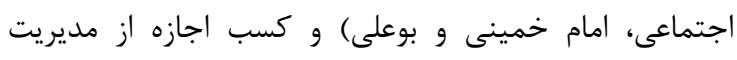

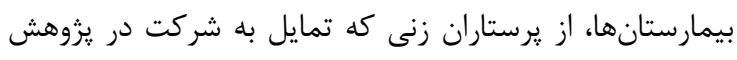

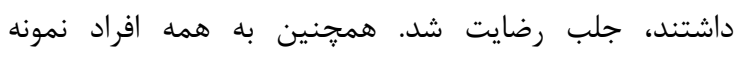

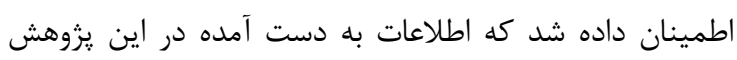

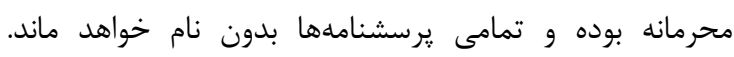

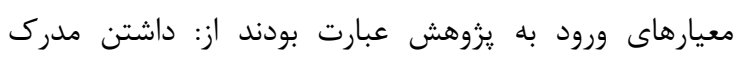

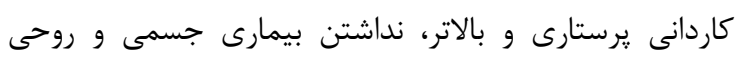

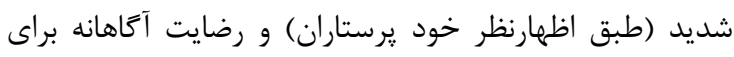

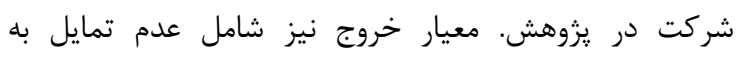

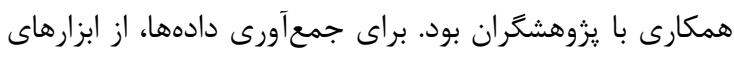

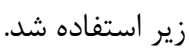

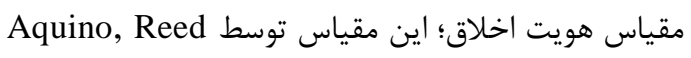

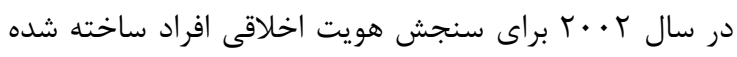

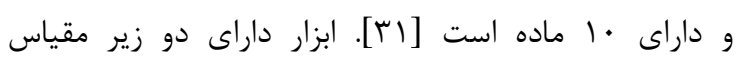

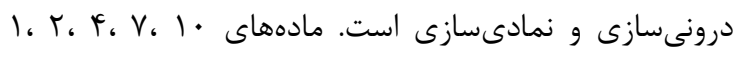

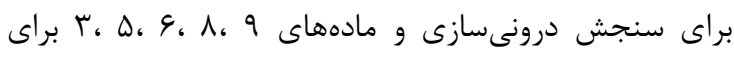

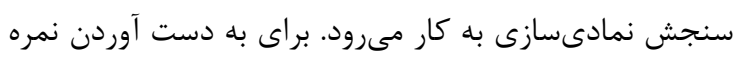

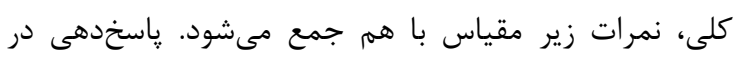

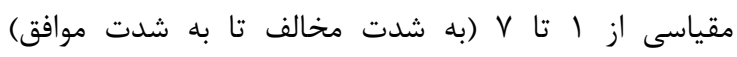

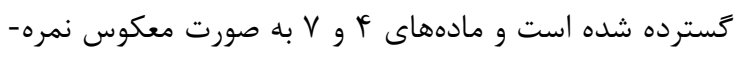

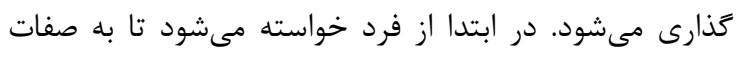

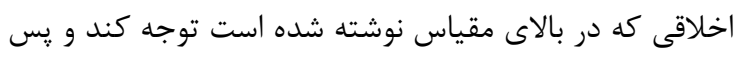

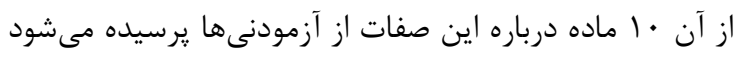

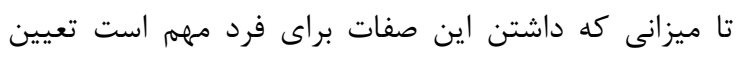

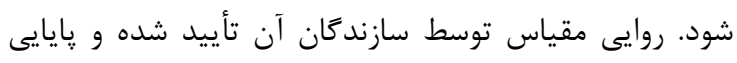

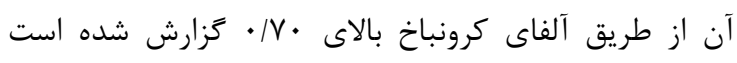

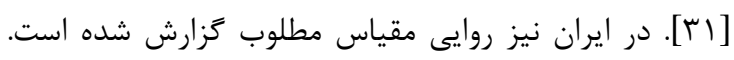

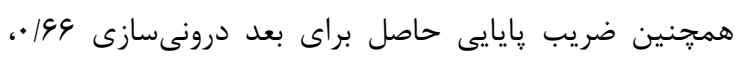

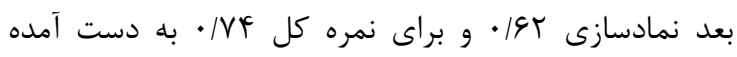




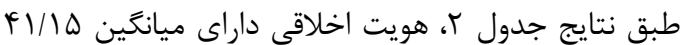

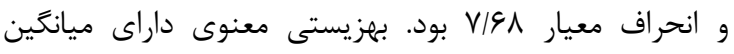
T/NF

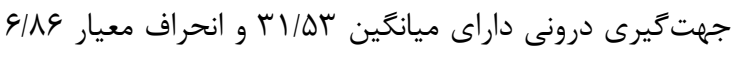

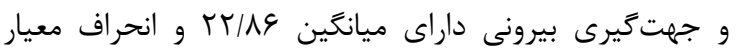

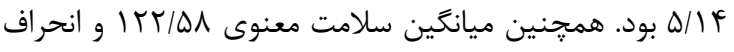

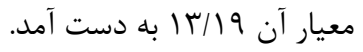
يس از تاييد مفروضه نرمال بودن دادهها از طريق آزمون

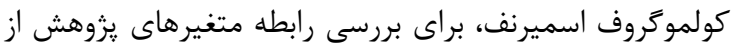

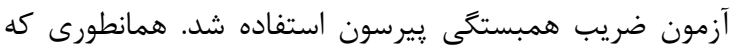

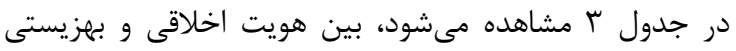

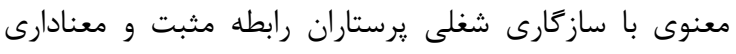

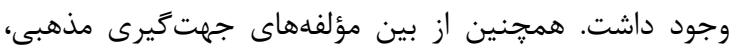

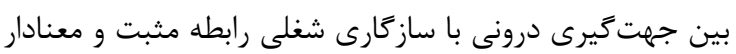

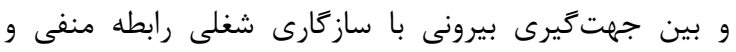
معنادارى مشاهده شد.

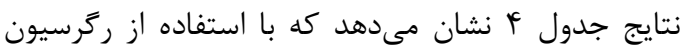

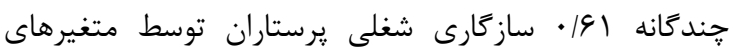

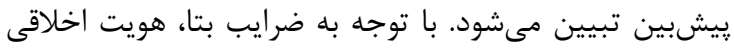

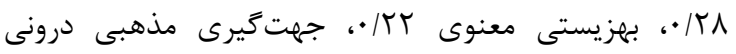

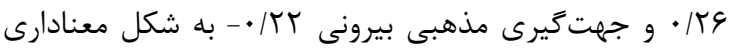

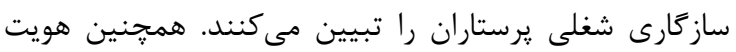

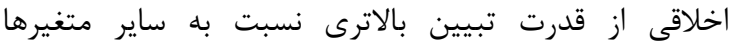

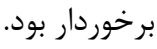

جدول ؟: ميانگين و انحراف معيار متغيرهاى يزوهش

\begin{tabular}{|c|c|c|c|}
\hline انحراف معيار & ميانتين & & متغير \\
\hline$V / \& \Lambda$ & $f \backslash / 10$ & & هويت اخلاقى \\
\hline$\Delta / \cdot \varphi$ & rN/VF & & بهزيستى معنوى \\
\hline$\Delta / / F$ & $\begin{array}{l}r I / \Delta r \\
\text { Tr/AG }\end{array}$ & دبرونى & جهت گيرى مذهبى \\
\hline $11 / 19$ & $\mid r T / \Delta \Lambda$ & & ساز كارى شغلى \\
\hline
\end{tabular}

جدول "ا: ضرايب همبستكى هويت اخلاقى، بهزيستى معنوى و جهت گيرى مذهبى با سازگًارى شغلى يرستاران

\begin{tabular}{|c|c|c|c|}
\hline سازتارى شغلى & آماره & & متغير \\
\hline . & ضريب پيرسون & & هويت \\
\hline$\cdot 1 \cdot \cdot 1$ & سطح معنى دارى & & اخلاقى \\
\hline • & ضريب يِرسون & & بهزيستى \\
\hline$\cdot 1 \cdot \cdot 1$ & سطح معنى دارى & & معنوى \\
\hline$\cdot 109$ & ضريب پيرسون & & \\
\hline$\cdot 1 \cdot \cdot 1$ & سطح معنى دارى & درونى & جهت گيرى \\
\hline$-\cdot / \Delta T$ & ضريب يرسون & & مذهبى \\
\hline$\cdot 1 \cdot \cdot 1$ & سطح معنى دارى & بيروى & \\
\hline
\end{tabular}

مقياس مىتواند بخيرد، • •1 و هايينترين آن عب مىباشد.

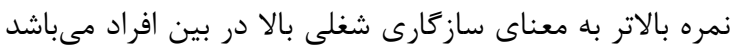

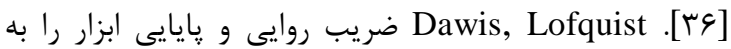

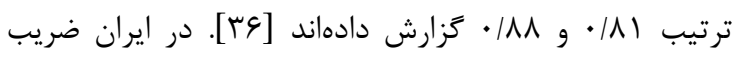

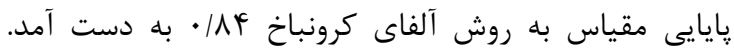

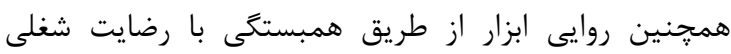

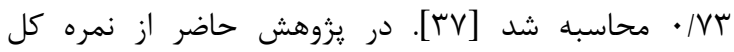

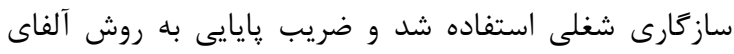

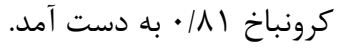

براى تجزيه و تحليل دادهها در بخش آمار توصيفى از داز

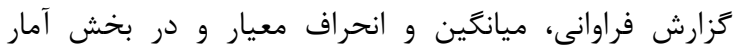

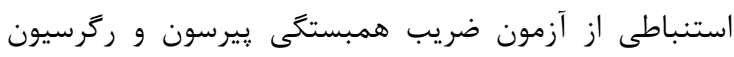

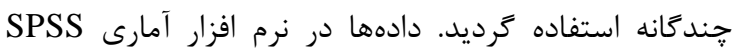

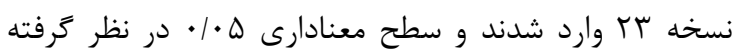

\section{1. إْتهن}

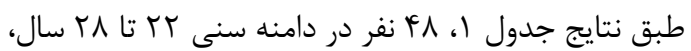

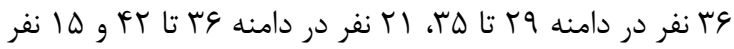

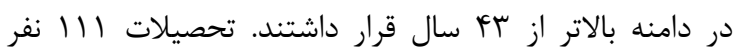
كاردانى و كارشناسى و 9 نفر كارشناسى ارشد بود.

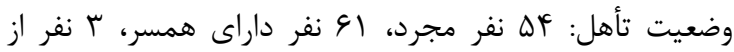

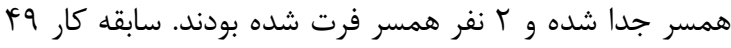

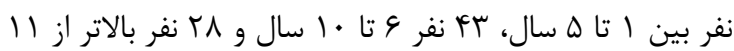

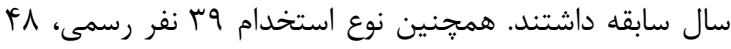

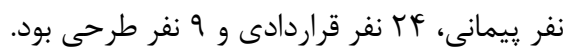

جدول (: مشخصات دموكرافيك افراد شركت كننده در مطالعه

\begin{tabular}{|c|c|c|c|}
\hline $\mathbf{P}$ & $\mathbf{F}$ & شاخص & متغير \\
\hline f. & $\uparrow \wedge$ & tN-tt & \multirow{4}{*}{ سن } \\
\hline$r \cdot$ & rद & $r \Delta-r q$ & \\
\hline$I V / D$ & rI & Fr-rg & \\
\hline $1 \pi / \Delta$ & 10 & سץ و بالاتر & \\
\hline $9 r / 6$ & 111 & كاردانى و كارشناسى & \multirow{2}{*}{ تحصيلات } \\
\hline$V / Q$ & 9 & كارشناسى ارشد & \\
\hline$F \Delta$ & $\Delta F$ & مجرد & \multirow{4}{*}{ وضعيت تأهل } \\
\hline$\Delta \cdot / \Lambda$ & 91 & داراى همسر & \\
\hline$r / Q$ & r & از همسر جدا شده & \\
\hline $1 / V$ & r & همسر فوت شده & \\
\hline$r \cdot / \Lambda$ & $4 q$ & $1-\Delta$ & \multirow{3}{*}{ سابقه كار } \\
\hline$r \Delta / \Lambda$ & pr & $9-1$ & \\
\hline$r M / F$ & rA & II سال و بالاتر & \\
\hline$r T / \Delta$ & rq & رسمى & \multirow{4}{*}{ نوع استخدام } \\
\hline$r$. & $\uparrow \wedge$ & يِيمانى & \\
\hline$r \cdot$ & TF & قراردادى & \\
\hline$V / \Delta$ & 9 & طرحى & \\
\hline
\end{tabular}

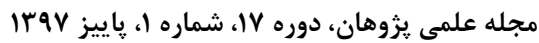


جدول f: خلاصه نتايج تحليل ركرسيون خندگًانه استاندارد متغيرهاى يزوهش

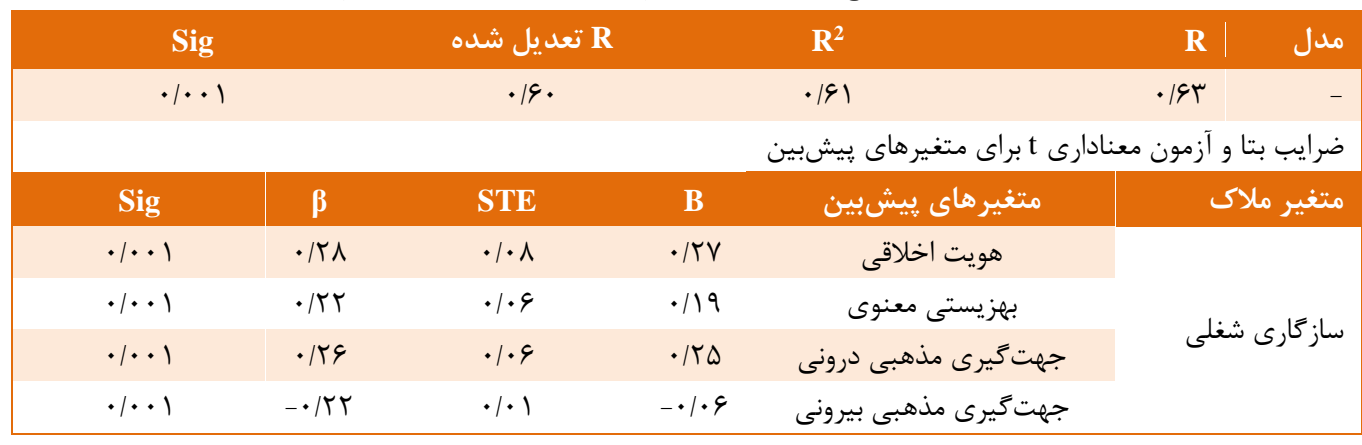

شناخت و ادراى از خود متمركز بر شمارى از صفات اخلاقى

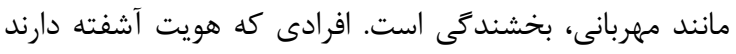

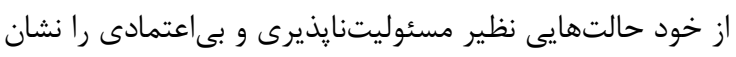

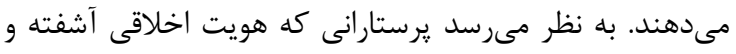

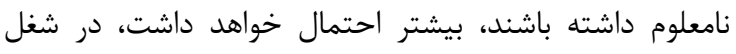

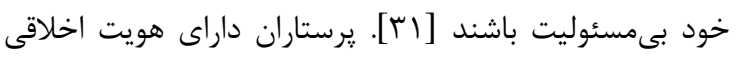

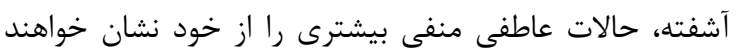

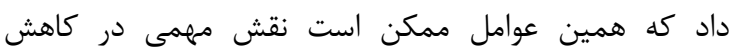

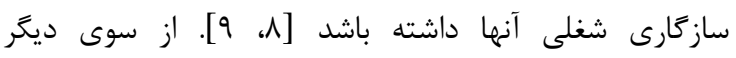

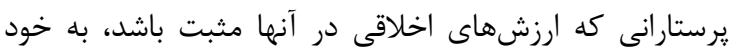

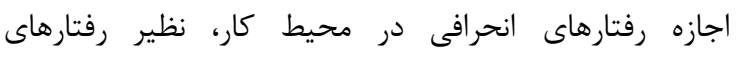

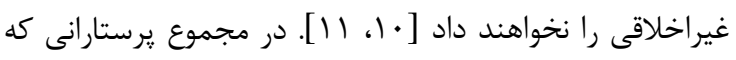

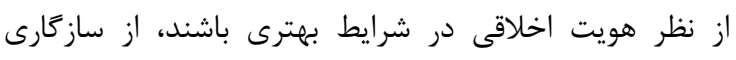

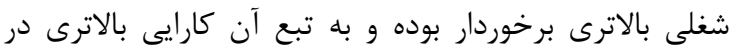

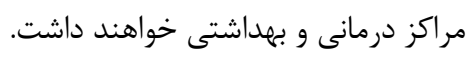

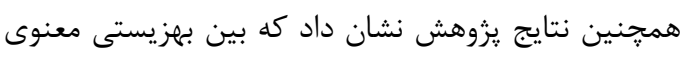

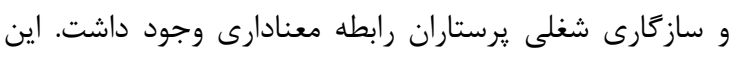

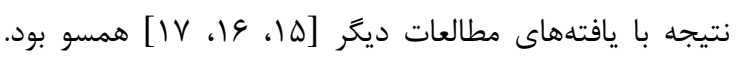

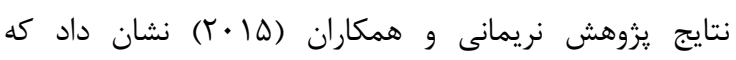

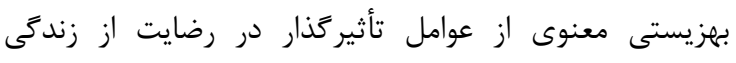

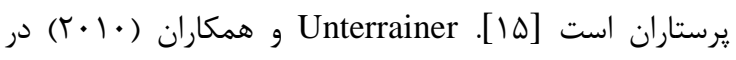
يزوهش خود به اين نتيجه رسيدند كه بهزيستى معنوى بالا،

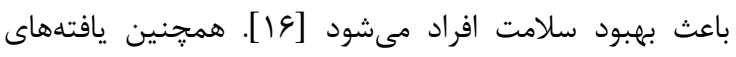

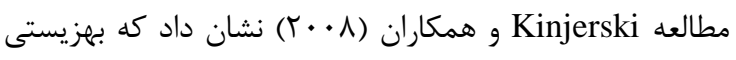

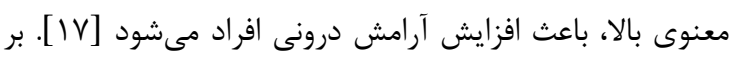

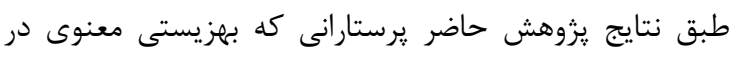

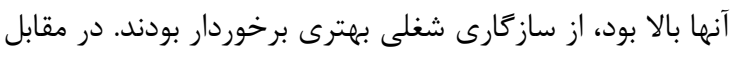

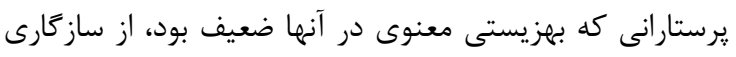

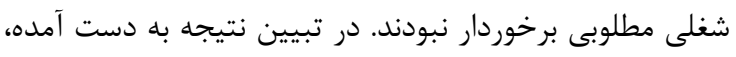

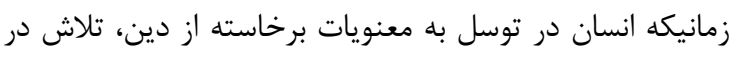

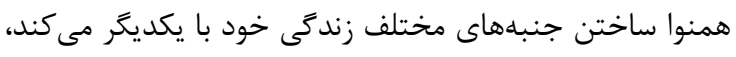

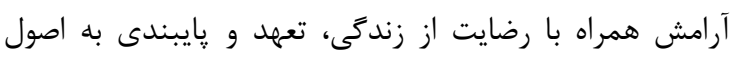

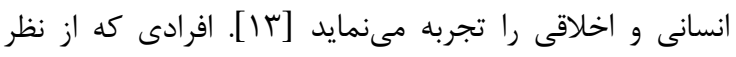

يزوهش حاضر با هدف تعيين رابطه هويت اخلاقى،

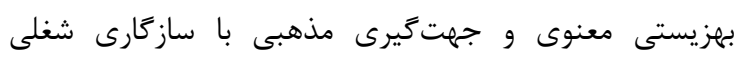

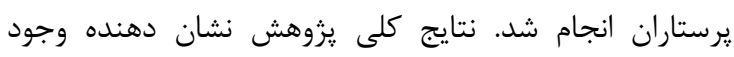

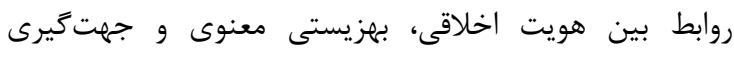

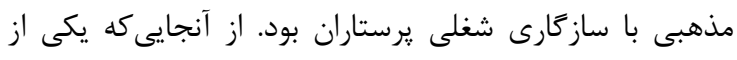

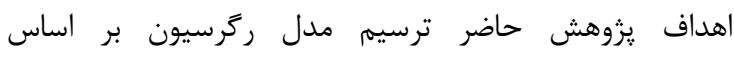

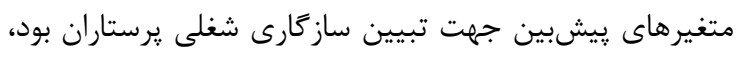

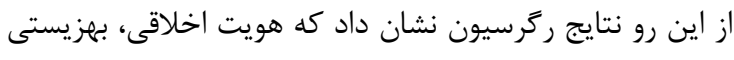
معنوى و جهت

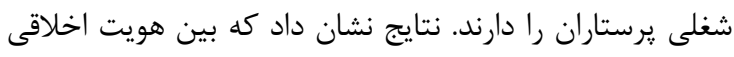

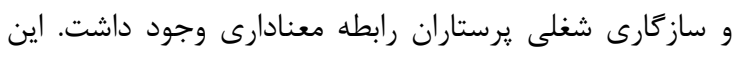

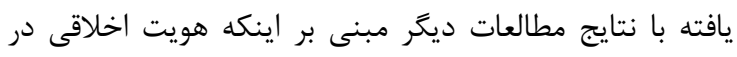

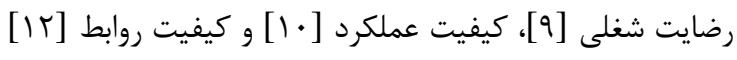

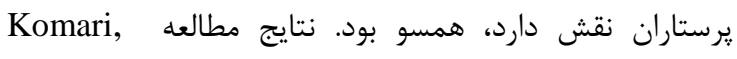
Djafar

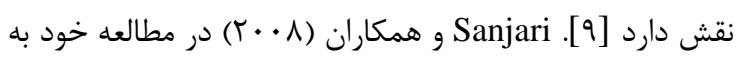
اين نتيجه رسيدند كه هويت اخلاقى در بهببود عملكرد افراد

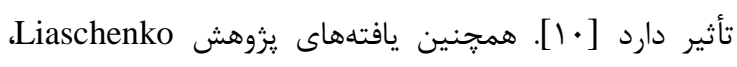
(Y) Peter

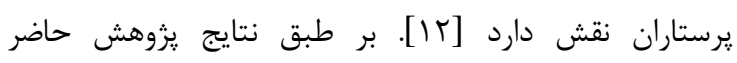

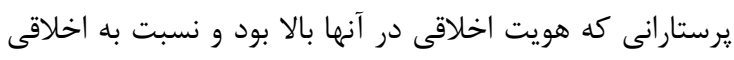

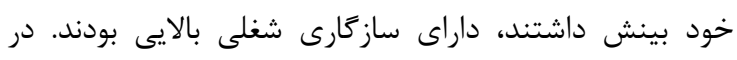

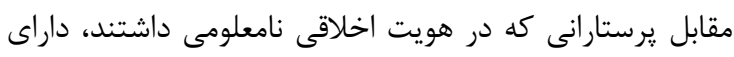

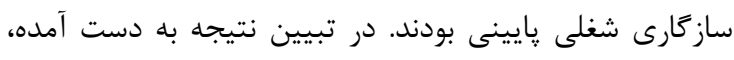

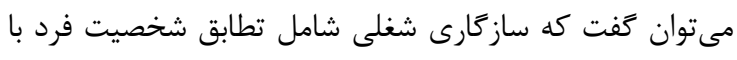

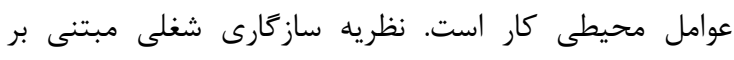

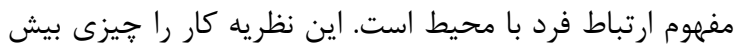

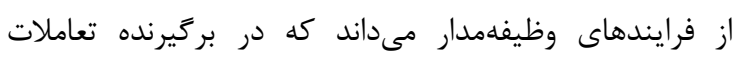

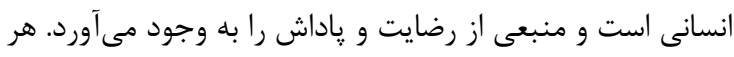
فردى انتظار دارد شغلش باعث خشنودى و سلامت و و اعتبار وى رى إنى

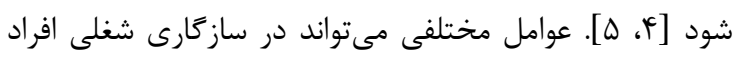

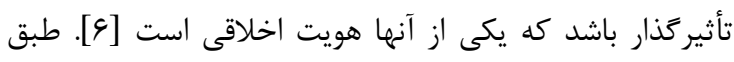

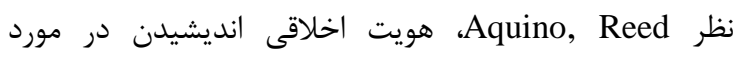


ساير شهرها با مشكل مواجه مى كند. بنابراين پِيشنهاد مىشود يزوهشى مشابه اين مطالعه روى يرستاران در شهرهاى ديخر

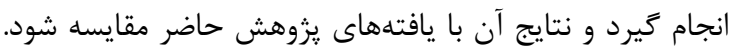

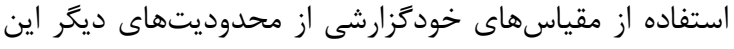

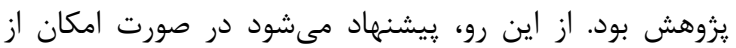

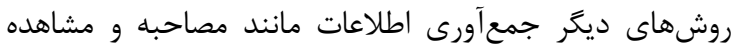

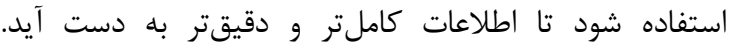
علاوهبراين در اين يزوهش از روش نمونهگيرى در دسترس

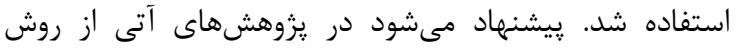
نمونه گيرى تصادفى بهره گرفته شود تا تعميم نتايج با اطمينان بيشترى امكانيذير باشد.

نتيجه تيرى در نهايت مىتوان بيان نمود كه هويت اخلاقى، بهزيستى معنوى و جهت

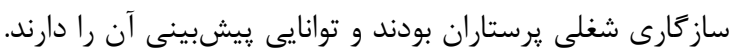

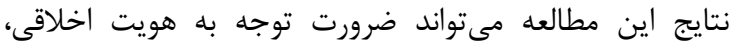

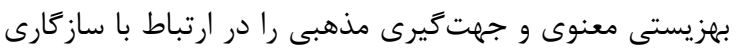

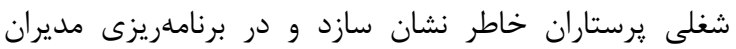

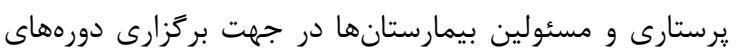

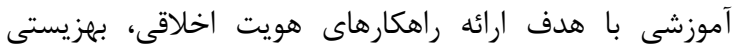
معنوى و جهت

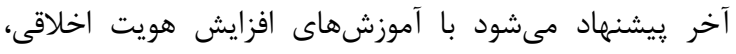

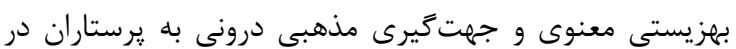
بهبود سازكارى شغلى كمى كرد.

$$
\text { تشكر و قرو فاذى }
$$

از مسئولان و برستاران بيمارستانهاى شهر اردان اردبيل كه در

يزوهش حاضر همكارىهاى لازم را انجام دادند تشكر و قدردانى لئي

$$
\text { مى شود. }
$$

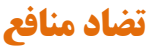
اين مطالعه براى نويسندَان هيجَّونه تضاد منافعى نداشته

\section{REFERENCES}

1. Chien WT, Yick S. An Investigation of Nurses' Job Satisfaction in a Private Hospital and Its Correlates. Open Nurs J. 2016; 10: 99-112. PMCID: PMC4895062.

2. Lou JH, Li RH, Yu HY, Chen SH. Relationships among self-esteem, job adjustment and service attitude amongst male nurses: a structural equation model. J Clin Nurs. 2011; 20(5-6): 864-72. PMID: 21118324.

3. Hassani M, Badalian A. A study of relationship between cultural intelligence with job adjustment and organizational trust. Q J Career Organ Couns. 2014; 5(17): 75-88. (Persian)

4. Sohrabian A, Modaresi S, Yousefi F. The Investigation of Relationship between Organizational Climate and Job Satisfaction among Occupied Nurses in Psychiatric Hospitals of Qods, Tohid and Besat. Shenakht J Psychol
معنويت و مذهب قوى باشند، از نظر اخلاقى نيز خود را مسئول

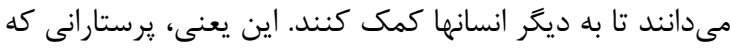

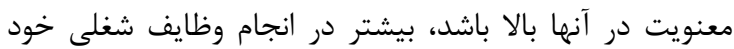

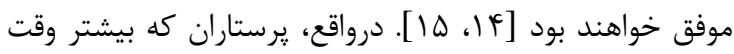

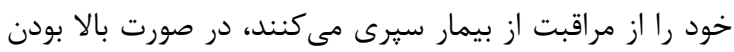

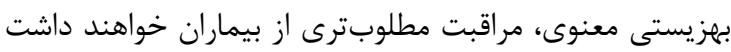

[ $|1,| \vee, \mid 9]$

همجنين يافتههاى يُوهش نشان داد كه بين جهت

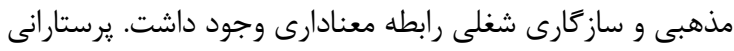

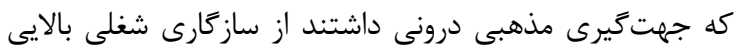

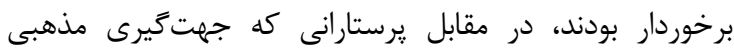

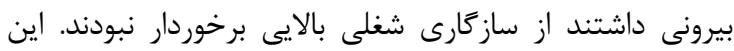

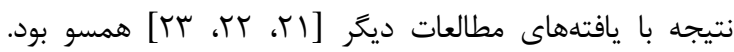

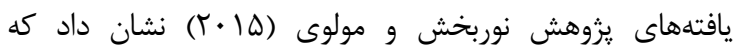
جهت

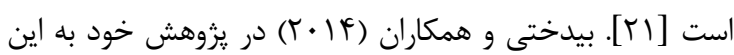
نتيجه رسيدند كه جهت

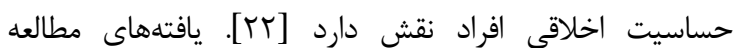

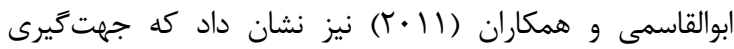
مذهبى در عملكرد شغلى يرستاران نقش دارد [سז]. در تبيين

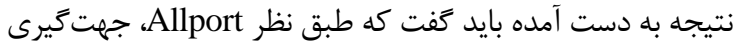
مذهبى رويكرد كلى شخص است كه از دين شخص اتخاذ شده

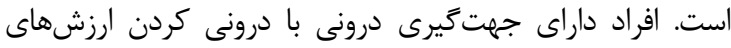

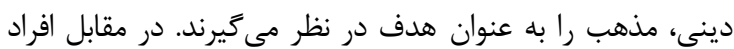
داراى جهت

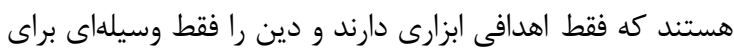
نيل به اهداف ديخر در نظر مى

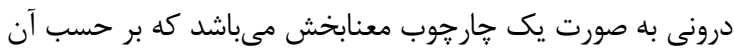

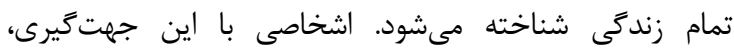

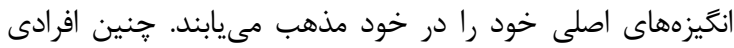

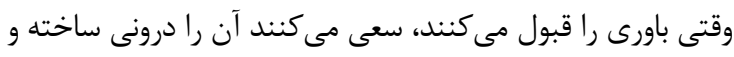
به طور كامل دنبال كنند كه تمامى اين عوامل باعث بهبيود

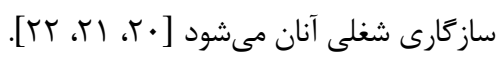

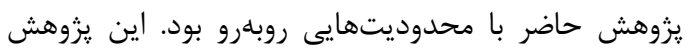

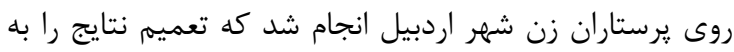

Psychiatr. 2018; 4(4): 34-43. (Persian)

5. Kelbiso L, Belay A, Woldie M. Determinants of Quality of Work Life among Nurses Working in Hawassa Town Public Health Facilities, South Ethiopia: A Cross-Sectional Study. Nurs Res Pract. 2017; 2017: 5181676. PMCID: PMC5742902.

6. Ranjbar H, Joolaee S, Vedadhir A, Abbaszadeh A, Bernstein C. Becoming a nurse as a moral journey: A constructivist grounded theory. Nurs Ethics. 2017; 24(5):583-97. PMID: 26754971.

7. Jia F, Krettenauer T. Recognizing Moral Identity as a Cultural Construct. Front Psychol. 2017; 8: 412. PMID: 28377737.

8. Hardy SA, Bhattacharjee A, Reed A, Aquino K. Moral identity and psychological distance: The case of adolescent 
parental socialization. J Adolesc. 2010; 33: 111-23.

9. Komari N, Djafar F. Work Ethics, Work Satisfaction and Organizational Commitment at the Sharia Bank, Indonesia. Int Bus Res. 2013; 6(12): 107-17.

10. Sanjari M, Zahedi F, Larijani B. Ethical codes of nursing and the practical necessity in Iran. Iranian J Publ Health. 2008; 37(1): 22-7. (Persian)

11. Marnani Barati A, Georgian H, Khatami Firouz Abadi A, Haqqani H, Marandi F. Patients' views of nurses and nursing ethics rules a hospital in Tehran University of Medical Sciences. Iran J Med Ethics Hist Med. 2012; 7(23): 63-79. (Persian)

12. Liaschenko J, Peter E. Fostering Nurses' Moral Agency and Moral Identity: The Importance of Moral Community. Hastings Cent Rep. 2016; 46(1): 18-21. PMID:27649913.

13. Fisher J. Item response theory analysis of the spiritual wellbeing questionnaire Religions. Pers Individ Dif. 2005; 35(8):1107-21.

14. Golparvar M. Construt Islamic Spiritual Capital and Spiritual Wellbeing Short-Form Scales. Relig Anthropol. 2015; 11(32), 167-88. (Persian)

15. Narimani M, Porzoor P, Atadokht A, Abbasi M. The role of spiritual well-being and religious adherence in predicting marital satisfaction among nurses. J Clin Nurs Midwifery. 2015; 4(2): 1-10. (Persian)

16. Unterrainer HF, Ladenhauf $\mathrm{KH}$, Moazedi ML, WallnerLiebmann SJ, Fink A. Dimensions of Religious/Spiritual Well-Being and their relation to Personality and Psychological Well-Being. Pers Individ Dif. 2010; 46(3):192-97.

17. Kinjerski V, Skrypnek, Berna J. Four Paths to Spirit at Work: Journeys of Personal Meaning, Fulfillment, WellBeing, and Transcendence Through Work. Career Dev Q. 2008; 56: 319-29.

18. Fisher J. Staffs and family members, spiritual well-being in relation to help for residents with dementia. J Nurs Educ Pract. 2012; 2(4): 77-85.

19. Lin CL, Yeh JT, Wu MC, Lee WC. Religious Orientation, Endorser Credibility, and the Portrayal of Female Nurses by the Media. J Relig Health. 2015; 54(5):1699-711. PMID:25062929.

20. Amirsardari L, Azari Sh, Esmali Kooraneh A. The Relationship Between Religious Orientation, and Gender with a Cognitive Distortion. Iran J Psychiatry Behav Sci. 2014; 8(3): 84-9. PMCID: PMC4359730.

21. Norbakhsh A, Molavi H. The Relationship of Spiritual Intelligence and Religious Beliefs with Feelings of Inferiority and Violence in Students. Knowl Res Appl Psychol. 2015; 16(1): 59: 4-12. (Persian)

22. Beydokhti TB, Tolide-ie H, Fathi A, Hoseini M, Gohari Bahar S. Relationship between religious orientation and moral sensitivity in the decisionmaking process among nurses. Iranian J Med Ethics Hist Med. 2014; 7(3): 48-57. (Persian)

23. Abolghasemi A, Moradisoroush M, Narimani M, Zahed A. The relationship between personal initiative, religious orientation and organizational social capital and workers job performances in the productive centers. Knowl Res Appl Psychol. 2011; 12(43): 86-94. (Persian)
24. Salimi Bajestani H, Hosseini Ghomi T, Zakeri N. Relationship religious orientation and hope with health anxiety among women nurses in Imam Khomeini hospital of Tehran. Iranian J Nurs Res. 2014; 9(1): 17-24. (Persian)

25. Mohamadi J, Gholamrezai A, Azizi A. The relationship between Religious Orientation and Mental Health among female nurses working in public hospitals of Tabriz in 2014. J Sabzevar Uni Med Sci. 2016; 22(6): 1080-87. (Persian)

26. Khoshnood G, Shayan N, Babaie Amiry N, Ashoori J. Relationship between Religious Orientation, Happiness, Locus of Control and Coping Strategies, and Spiritual Wellbeing Among Nursing Students. Supplementary Mental Health. J Res Dev Nurs Midwifery. 2016; 12(3): 9-18. (Persian)

27. Sotoodeh H, Shakerinia I, Kheyrati M, Dargahi S, Ghasemi Jobaneh R. Surveying the relationship between spiritual and moral intelligence and the psychological well-being of nurses. Medical Ethics and History of Medicine .2016; 9(1): 63-73. (Persian)

28. Ashoori J. Prediction nurse's job burnout based on social capital, perceived social support and organizational citizenship behavior. Pajouhan Sci J. 2017; 15(2) :13-9. (Persian)

29. Alipoor R, Ebrahimi A, Omidi R, Hedayati A, Ranjbar H, Hosseinpour S. Depression, anxiety, stress and related demographic variables in nurses of Valiasr hospital in Fasa University of Medical Sciences in 2014. Pajouhan Sci J. 2015; 13 (4): 51-9. (Persian)

30. Cunningham JB, McCrum Gardner E. Power, effect and sample size using G Power. Practical issues for researchers and members of research ethics committees. Evidence Based Midwifery. 2007; 5(4): 132-6.

31. Aquino k, Reed A. The self- importance of moral identity. J Pers Soc Psychol. 2002; 83, 1423-40.

32. Azimpor A, Nisi A, Shahni M. Validation the Measure of "the Self-importance of Moral Identity" on University Students. J personal Individual Differ. 2014; 3(4): 19-38. (Persian)

33. Samadifard HR. The relationship between spiritual wellbeing and religious belief with a life expectancy of diabetic patients. Islam Health J. 2015; 2(2): 44-51. (Persian)

34. Allport, Gordon W. The Person in Psychology; Selected Essays. Boston: Beacon Press, 1968. https://www.amazon.com/ Person-Psychology-Selected-Essays/dp/0807029769.

35. Sadeghi S, Sadeghi O, khodadadi Z, Tavakolizadeh J, Tolidei $H$. The relationship between religious orientation and psychological well-being in Students of medical university of Gonabad in 1390-91. Islam Health J. 2015; 1(4): 57-63. (Persian)

36. Dawis RV, Lofquist LH. A psychological theory of work adjustment: An individual differences model and its applications. Stoughton, Massachusetts: Books on Demand; 1991.

37. Shahrabi L. Exploring the concepts and factors of Dawis \& Lofquist job adjustment theory and making a questionnaire between women teachers of Tehran area 15 at 1389-1390 year. Q J Career Organ Couns. 2012; 4(12): 162-80. (Persian) 